\title{
The Degree of Availability of Crisis Management Elements in the Boards of Directors of Jordanian Football Sport Clubs in Light of the Coronavirus (COVID-19) Pandemic
}

\author{
Nedal Ahmad Alghafary ${ }^{1, *}$, Khalaf Waleed Diabat ${ }^{2}$, Mohammad Ahmad Hamed Abuhawileh ${ }^{3}$ \\ ${ }^{1}$ Teaching Curricula in Physical Education, Al-Balqaa Applied University, Jordan \\ ${ }^{2}$ Department of Teaching and Supervision, Sport Sciences College, Jordan \\ ${ }^{3}$ Ministry of Education, Jordan
}

Received April 15, 2021; Revised May 27, 2021; Accepted June 25, 2021

\begin{abstract}
Cite This Paper in the following Citation Styles
(a): [1] Nedal Ahmad Alghafary, Khalaf Waleed Diabat, Mohammad Ahmad Hamed Abuhawileh, "The Degree of Availability of Crisis Management Elements in the Boards of Directors of Jordanian Football Sport Clubs in Light of the Coronavirus (COVID-19) Pandemic," International Journal of Human Movement and Sports Sciences, Vol. 9, No. 4, pp. 781 - 790, 2021. DOI: 10.13189/saj.2021.090424.
\end{abstract}

(b): Nedal Ahmad Alghafary, Khalaf Waleed Diabat, Mohammad Ahmad Hamed Abuhawileh (2021). The Degree of Availability of Crisis Management Elements in the Boards of Directors of Jordanian Football Sport Clubs in Light of the Coronavirus (COVID-19) Pandemic. International Journal of Human Movement and Sports Sciences, 9(4), 781 - 790. DOI: $10.13189 /$ saj.2021.090424.

Copyright $\odot 2021$ by authors, all rights reserved. Authors agree that this article remains permanently open access under the terms of the Creative Commons Attribution License 4.0 International License

\begin{abstract}
The study aimed at investigating the degree of availability of crisis management elements in the boards of directors of Jordanian football sport clubs in light of the Corona virus pandemic (COVID-19). The study adopted the descriptive cross-sectional research approach. The sample of the study comprised of (208) members of clubs boards of directors. The study utilized a 5-domain. The findings revealed that the degree of availability of crisis management elements in the boards of directors of Jordanian football sports clubs in light of the Coronavirus (COVID-19) pandemic was at a moderate degree. In addition, there were no statistically significant differences in the degree of availability of crisis management elements in Football sport clubs' boards of directors referred to the variables (administrative experience, educational qualification, team rank). The study recommended the necessity of activating the role of crisis management elements in sports bodies and institutions and the need to enact legislation and laws that oblige members of sports club boards of directors to obtain training courses in the field of crisis management.
\end{abstract}

Keywords Crisis Management, Boards of Directors,
Jordanian Sports Clubs, COVID-19

\section{Introduction}

Sports clubs are considered among the administrative and social institutions that include many employees, such as members, coaches, players and the masses. These clubs have many buildings and sports facilities and tools that require proper management to achieve the club's goals, and continue running the club's affairs in an administrative manner that depends on the scientific foundations in sports management to bypass the obstacles hindering the development of the club. The world today is witnessing vast changes that are full of crises and challenges in different areas of life, and we are living current days a critical crisis that imposes major global challenge in the field of health, which is the spread of the Coronavirus pandemic (COVID-19). This disease imposed a great challenge before all sectors, especially the sports and youth sector, which prevented many sports 
facilities and clubs from carrying out their activities.

Given that dealing with crises requires realistic scientific planning based on prior prediction of the occurrence of any emergency, preparedness and intervention in a realistic and systematic manner, this requires a wise administration with both scientific knowledge and administrative experience to cope with the crises and consequences facing these clubs.

Wilson [1] argues that it is necessary to assess the degree of readiness of administrative decision-makers in dealing with crises and the availability of pre-prepared crisis management plans, in addition to developing plans and interventions necessary to manage the post-consequences of the crises.

Sports management depends heavily on the human component and the method of interaction between individuals, in addition to coordination between their various efforts. This is the fact that gives the administration a special capacity as it is a social and humanitarian process on the one hand and economic and political on the other hand. This requires the administrative process to become a rational process that achieves its goals for running the available capabilities while ensuring the best management environment for the work of the human component with the least possible effort [2]

Since the current era is witnessing many events, which are portrayed by diversity and speed, in all economic, political and sports fields, they prevent the development and improvement of these institutions and stand as an impregnable and strong barrier towards the growth and development of bodies and institutions when they go through various crises,

Crises occur due to disturbances in the institution's conditions that are characterized by instability and whose consequences may lead to dispersion and the inevitable transition to a more negative situations, as they constitute an unpredicted serious threat that creates confusion, which limits the capability of making sound and correct decisions [3]

Esleem [4] reports that the issue of crisis management is an approach and policy expressing the future scene for the interaction and adaptation with the developments of contemporary life, in addition to confronting it in rational systematic approaches; So that it can reformulate the imbalance resulted of its passing through various crises and to gain higher capacity and harmony with the crisis and with the capabilities of the institution.

Moreover, Phelps [5] indicated that the process of crisis management encounters a set of barriers that must be identified and studied in order to find appropriate solutions and measures taken to mitigate them. The rapid progress at the technological level and the sequential changes taking place lead to the emergence of difference kinds of more complex and ambiguous situations that are called crises, which must be dealt with to mitigate them or limit their impact on people, institutions and assets.

Since crises have many political, economic and social aspects, which must be dealt with during the management of the crisis and under its pressure, it is difficult to define a comprehensive concept of the crisis. However, crises always share a set of characteristics such as the threat to resources and goals, the limited time available to take Decisions, lack and inaccuracy of information, and surprise, which can limit crisis management practices.

Qutaish [6] argues that the success of crisis management depends mainly on the ability of decision-makers to adapt psychological pressures and stress during the management of the crisis, the enjoyment of a high degree of wisdom and vigilance, not to rush to take decisions and this is done through the availability of information, data and correct approaches to share them and follow an interventional mechanism characterized by a high level of organizing. At this point, the role of the administration emerges through focusing on the media and psychological role in managing the affairs of the crisis to mitigate its effects. Al-Hafni [7] ensures that the media contributes significantly to mitigating the effects of the crisis and helps the administration in reducing the bad reputation that often afflicts institutions, and curbing rumors that may contain extortion from others.

\section{Statement of Problem}

The issue of crisis management is one of the significant administrative aspects that must be available in institutions, specifically in the field of sports management. Crises in the sports field are diverse in forms and causes. There are administrative, economic, technical, medical and social crises that clubs and sports institutions may be exposed to, and these obligations need a wise management either to avoid, deal or prevent them.

Various theoretical and empirical studies that were carried out to address the crisis management have highlighted the necessity of the availability of crisis management elements in sports institutions. Among these studies are Al-Momani [8], Al-Masaadeh [9] study, Ashour [10], and Al-Maharmeh [11] study, where the results of these studies stressed the necessity of having crisis management elements to overcome the obstacles and challenges that limit the progress of these institutions. In addition, Al-Shamrani (2003) study showed that there is a decrease in the degree of availability of crisis management elements in higher education institutions in Saudi Arabia. These days, people are living a serious crisis affecting the health sector (Coronavirus pandemic) (COVID-19), which significantly affected different sectors, including clubs and sports institutions, which led to the limitation of the normal establishment of activities and resulted in the postponement of the establishment of many sports activities, on top of these sports the Olympic Games that were supposed to be held in Tokyo (2020). 
However, its establishment was postponed due to this health crisis. In the Hashemite Kingdom of Jordan, as many other countries, people are experiencing the consequences of this crisis, as Jordanian sports clubs and sports championships have been touched by this global pandemic, specifically football clubs. Football is the most popular game in the world, and this was reflected in the performance of the players, their economic situation and the results of sports clubs. Since researchers are specialize in the field of sports and keeping pace with the local and international sports movement, the study problem was formulated focusing on identifying the degree of availability of crisis management elements in the Jordanian football sport clubs' boards of directors in light of the Coronavirus (COVID-19) pandemic.

\section{In Light of That, this Study Aimed to}

1. determine the degree of availability of crisis management elements in the boards of directors of Jordanian football sports clubs in light of the Coronavirus (COVID-19) pandemic.

2. identify the differences in the elements of crisis management referred to the variable (administrative experience, educational qualification, team rank).

The study questions are as follows:

- The first question: What is the degree of availability of crisis management elements in the boards of directors of Jordanian football sports clubs in light of the Coronavirus (COVID-19) pandemic?

- The second question: are there significant differences in the elements of crisis management referred to the variable (administrative experience, educational qualification, team rank).

\section{The Significance of the Study}

The significance of the study stems from the following:

1. Focusing on the crisis management elements of the boards of directors of Jordanian football sports clubs in light of the Coronavirus (COVID-19) pandemic.

2. Providing decision-makers in sports clubs with the results of this study in order to make appropriate decisions to develop the work of sports clubs administrations to find out their strengths and weaknesses in light of the Coronavirus pandemic (COVID-19).

3. Paving the way for researchers to conduct more scientific studies on crisis management in the sports field.

\section{The Study Definitions (Operational Definitions)}

Crisis management: are the procedures and steps taken by the institution (the club) to overcome the barriers and challenges in a sound scientific manner based on management elements that begin with realistic planning and sound prediction to encounter any emergency in the future.

Boards of directors: A group of individuals who are elected by the club's general body to manage the club's affairs and achieve its goals so that they have experience and knowledge in sports management affairs.

Jordanian Sports Clubs: A sports organization licensed by the Ministry of Youth and registered with the Jordan Football Association (JFA) and playing in the Federation championships at the level of the professional league and the first class.

The Coronavirus (COVID-19) pandemic is a global pandemic that emerged due to the outbreak and spread of the Coronavirus (COVID-19), which is rapidly spreading, contagious, and expanding its scope worldwide, which affected all sectors.

\section{Previous Studies}

Al-Masaadeh [9] study aimed at identifying the availability of crisis management elements in sports institutions in Jordan. The study adopted the descriptive approach. A valid and reliable questionnaire examining the elements of crisis management and their obstacles was administered to the study participants. The findings of this study revealed that the crisis management elements are available in a moderate degree in sports institutions with a medium degree in all stages, in addition to the barriers that limit the availability of crisis management elements that were available moderately. The results of the study also reported that there were no statistically significant differences in the elements of crisis management due to the variables of age, educational qualification, years of experience and gender, except for the institution variable, as there were statistically significant differences in favor of the Olympic committee and sports federations. The study recommended the necessity of ensuring the availability of crisis management elements at a high degree by contributing to activating the elements of crisis management in sports institutions and conducting training courses for administrators in the field of crisis management.

In another study carried out by Al-Shamrani [12] study aimed at determining the availability of crisis management elements and the barriers that limit their availability within administration in higher education institutions in the Kingdom of Saudi Arabia. The study found that five domains represented in the elements of crisis management were collectively available to a high degree and according to their significance as follows (damage containment, preparedness and prevention, learning, recovery, detection of alarming signs), where the alarming detection element was available at a moderate degree. In addition, the study pointed a low level availability of barriers that limit the availability of the crisis management elements. These barriers are ranked as 
following: (barriers related to communicating information, humanitarian barriers, and organizational barriers). Furthermore, the study results revealed that there were statistically significant differences in the crisis management elements referred to the variables of age, educational qualification, years of experience, job level, and the number of courses. In addition, there were no significant statistical differences in the crisis management elements referred to gender Variable.

Al-Mansouri [13] carried out a study that sought to identify the reality of the administrative behavior of educational leaders in secondary schools in the State of Qatar, in addition to identifying the problems encountering the school administration and approaches of crisis management. One of the most significant findings of this study was the necessity that the spirit of love, sympathy, respect and cooperation be restored among all school employees when dealing with educational crises, and recognizing the individuals' value in the school and their featured contributions to it.

Al-Farazi [14] conducted a study aimed to identify the types of crises encountering preparatory and secondary school principals and their assistants in the Sultanate of Oman, in addition to the approaches used to manage these crises from their viewpoints. The study sample comprised of preparatory and high school principals. The results of the study indicated that the responses of the study subjects on the five domains; the types of crises, and the approaches used by preparatory and secondary school principals and their assistants in the Sultanate of Oman were ranging between moderate and sub-moderate, as well as that there were statistically significant differences at the level of $(\alpha=0.05)$ referred to the job title variable. Furthermore, there were also statistically significant differences at the level of $(\alpha=0.05)$ between the mean scores of the participants' responses referred to the region variable.

Birkland [15] performed a study entitled "Disasters and Ineffective Crisis Management Plans", which sought to evaluate the effectiveness of crisis management plans during exposure to a crisis. The study sample comprised of (6) elementary, middle and high schools in Detroit, USA. The results of the study reported the ineffectiveness of the crisis management plans developed in participating schools, in addition to the fact that schools experiencing a crisis do not learn from their previous experiences.

Admns \& kristonis [16] conducted a study entitled "Analyzing the readiness of schools in the United States for crisis management". This study aimed to analyze crisis management plans in schools that were exposed to previous crises. The study sample consisted of (6) intermediate and secondary schools that have been exposed to previous crises. The results of the study showed that schools that have been exposed to previous crises developed effective plans for managing crises in the future, and that the previous experience of schools can be used in terms of developing effective future plans for crisis management.

Abdel-Al [17] conducted a study aimed at identifying the approaches of crisis management of public school principals in the Gaza / Palestine governorates and their association to school strategic planning. The study sample consisted of all the study population subjects of government school principals in the governorates of Gaza. There is a positive correlation between the approaches of crisis management and school strategic planning, while there was a negative correlation between the escape approach and school strategic planning. Moreover, the results of the study ensured the awareness of school principals to the significance of coordination inside and outside the school and cooperation in encountering crises, and defining the role of all individuals in the school in Crisis Management.

Furthermore, Al-Momani [8] conducted a study that aimed at identifying the availability of the crisis management elements in the physical education colleges in the Jordanian universities. The study sample comprised of the academic teaching staff in the colleges of physical education. The study adopted the descriptive research approach. The study results indicated that there was a moderate level of availability of the crisis management elements (Detection of alarming signs, preparedness and prevention, damage containment, and recovery). On the other hand, the learning stage element was available at a low degree. Finally, the results of the study revealed that there were no significant statistical differences in the availability of the crisis management elements in the colleges of physical education referred to any of the study variables.

Al-Maharmeh [11] carried out a study that aimed at identifying the obstacles to crisis management in the sports activity departments in Jordanian universities from the perspectives of the managers of the sports activity departments, and to identify the effect of the university and educational qualification variables in identifying the barriers to crisis management in the sports activity departments. The study adopted the descriptive method. A questionnaire consisting of five domains human obstacles, organizational obstacles, economic obstacles, technological obstacles, information and communication obstacles) was used to collect data in this study. The study found that the domain of economic, technological and organizational obstacles has achieved a high degree, whereas human barriers and communication and information domains were ranked moderately. The study also revealed that there were no significant statistical differences referred to the university and educational qualification variables. The study recommended the necessity of the commitment of the sports activity departments to develop the necessary crisis management strategies when preparing sports programs to reach the goals. 
Al-Senani [18] conducted a study aimed at exploring the barriers of crisis management at Imam Muhammad bin Saud Islamic University from the perspectives of colleges deans, head of departments and college vice-deans. The study adopted the descriptive analytical research approach that was applied on a sample of (143) participants. One of the most important findings of the study was that the most crises that got a moderate degree of occurrence is the faculty exposure to incidents of theft, followed by leakage of the test questions for a number of courses. The study recommended the need to establish a specialized unit in crisis management at the college level that is affiliated to the university administration and be directly in charge for dealing with crises encountered by the college. Moreover, Kemala et al [19] carried out a study that explored the Indonesian athletes training during COVID-19 pandemic. The study found that online training is the most suitable approach in the current era to train those athletes. Furthermore, Alghafary [20] reported that there was significant shortage in $21^{\text {st }}$ century life skills in the physical curricula designed for university students in Jordan.

Through exploring the previous studies, the current study is characterized from previous studies in that it dealt with an issue of the degree of availability of crisis management elements in the boards of directors of Jordanian football sports clubs in light of the Coronavirus pandemic (COVID-19). The researchers benefited from the previous studies with regard to the methodology and the statistical processing of the present study's data.

\section{Method and Procedure}

\section{Research Design}

This is an exploratory, as it sought to determine the degree of availability of crisis management elements in the boards of directors of Jordanian football sports clubs in light of the Coronavirus pandemic (COVID-19). The descriptive survey research approach was adopted to fit the nature of the study.

\section{Research Population and Sample}

The study population consisted of all the members of the boards of directors of the Jordanian football clubs for the professional league and the first-class league registered in the Jordanian Football Association members of the Board of Directors $(n=234)$. Due to the small size of the study population, the study sample consisted of all the members of the study population $(n=208)$.

\section{The Study Instrument}

The study used the data collection tool developed by
Al-Masaadeh [9], which included items related to the crisis management elements in the following stages (alarm detection stage, preparedness and prevention stage, damage containment stage, recovery stage, learning stage). The questionnaire consisted of two parts:

Part I: Included the title and domains of the study, in addition to the demographic data of the study participants (Team rank, educational qualification, experience).

Part II: included the study domains and statements (alarm detection stage, preparedness and prevention stage, damage containment stage, recovery stage, learning stage).

\section{Validity and Reliability}

\section{- Data collection tool validity}

The researchers performed content validity through submitting the primary version of the questionnaire and its domains on a number of experts and jury members who are specialized and $\mathrm{PhD}$ holders in physical education, measurement and evaluation.

The researchers identified three levels (High, moderate, and low) based on the equation of length of interval. Therefore, low level was (less than 2.33), moderate level was $(2.34-3.67)$, and high level (3.68-5.00). Then, the researchers structured the domains and the statements of the questionnaire, and the final version of the study questionnaire consisted of 29 statements.

\section{- Data collection tool reliability}

To ensure the reliability of the data collection tool, the researchers calculated the reliability coefficient through administering the study questionnaire on a pilot sample consisted of 20 participants. The reliability coefficient was $(0.85)$, which is an acceptable value in the educational research studies.

\section{The Study Variables}

First: Independent variables

- The sports club, has two levels (Professional and first-class)

- Educational qualification, has three levels (Secondary, Diploma, Bachelor and higher).

- Administrative experience, has two levels (Less than 5 years, more than 5 years)

Second: Dependent variables, which include the participants' responses to all of the questionnaire domains

\section{The Study Procedure}

- Formulating the research problem and reviewing the theoretical literature and previous studies.

- Constructing the data collection tool and ensuring its validity and reliability based on the scientific validation procedure. 
- Distributing the electronic version of the study questionnaire on the heads and members of the boards of directors of football sport clubs during the period between February and March/2021.

- Results analysis and interpretation

- Providing a set of recommendations and suggestions

\section{Results and Discussion}

The first question: What is the degree of availability of crisis management elements in the boards of directors of Jordanian football sports clubs in light of the Coronavirus (COVID-19) pandemic?

To answer this question, mean and standard deviation scores of the sample responses were calculated on the stages of the degree of availability of crisis management elements in the boards of directors of Jordanian football clubs in light of the Coronavirus pandemic (COVID-19). The results are presented in table (1)

The results shown in table (1) indicated that the learning stage was ranked first with a mean score of (3.88) and a standard deviation (0.12) and a high availability degree. In the final rank was the "alarm detection" stage that got a mean score of (1.04) and a standard deviation of (0.18), which indicated a low level of availability. The total mean score of the participants' responses was (2.31) with a standard deviation of $(0.15)$, which indicated a moderate degree of availability.

In addition, mean and standard deviation scores were calculated for the statements of each domain separately. The results shown in table (2) represent the mean and standard deviation scores for the participants' responses on the statements of the "alarm detection" domain.

The results presented in table (2) indicated that statement number (24) stating that "The club management has the ability to define the crisis" was ranked first with a mean score of (1.19) and a standard deviation of (0.1), which indicated a low degree of availability. In addition, the statement number (29) stating that "The club management has an administrative team capable of analyzing the indicators of the occurrence of the crisis" was ranked in the final rank with a mean score of $(0.89)$ and a standard deviation of $(0.21)$, which indicated a low degree of availability. The whole domain scored $(1.04 \pm 0.18)$, which indicated a low degree of availability.

Table 1. Means and standard deviations of the participants' responses about the stages of the availability of crisis management elements in the boards of directorates of Jordanian football clubs in light of the Coronavirus pandemic (COVID-19)

\begin{tabular}{|l|l|c|c|c|}
\hline No & Stage & M & SD & Degree \\
\hline $\mathbf{1}$ & Learning & $\mathbf{3 . 8 8}$ & $\mathbf{0 . 1 4}$ & High \\
\hline $\mathbf{2}$ & Recovery & $\mathbf{3 . 0 3}$ & $\mathbf{0 . 1 3}$ & Moderate \\
\hline $\mathbf{3}$ & Preparedness and prevention & $\mathbf{2 . 1 5}$ & $\mathbf{0 . 1 2}$ & Low \\
\hline $\mathbf{4}$ & Containment / Damage Limitation & $\mathbf{1 . 4 3}$ & $\mathbf{0 . 1 6}$ & Low \\
\hline $\mathbf{5}$ & Alarm detection & $\mathbf{1 . 0 4}$ & $\mathbf{0 . 1 8}$ & $\mathbf{2}$ \\
\hline Total & & $\mathbf{2 . 3 1}$ & $\mathbf{0 . 1 5}$ & Moderate \\
\hline
\end{tabular}

Table 2. Means and standard deviation of the participants' responses to the availability of the crisis management elements among boards of directors of sports clubs on the "alarm detection" domain

\begin{tabular}{|c|c|c|c|c|}
\hline No & Statement & M & $\mathrm{SD}$ & Degree \\
\hline 24 & The club management has the ability to define the crisis & 1.19 & 0.1 & Low \\
\hline 25 & $\begin{array}{l}\text { The club management works by thinking about the indicators of the } \\
\text { occurrence of crises. }\end{array}$ & 1.17 & 0.21 & Low \\
\hline 26 & $\begin{array}{l}\text { The club management is working on spending less time to plan and } \\
\text { contemplate unexpected crises }\end{array}$ & 1.1 & 0.24 & Low \\
\hline 27 & There is interest from the club's management to discover the signs of the crisis & 1.01 & 0.23 & Low \\
\hline 28 & $\begin{array}{l}\text { The club management conducts periodic surveys to identify the likelihood of } \\
\text { crises. }\end{array}$ & 0.9 & 0.1 & Low \\
\hline 29 & $\begin{array}{l}\text { The club management has an administrative team capable of analyzing the } \\
\text { indicators of the occurrence of the crisis }\end{array}$ & 0.89 & 0.21 & Low \\
\hline \multicolumn{2}{|c|}{ Total } & 1.04 & 0.18 & Low \\
\hline
\end{tabular}


Table 3. Means and standard deviations of the participants' responses to the degree of availability of the crisis management elements related to the preparedness and prevention domain

\begin{tabular}{|l|l|c|c|c|}
\hline No & Statement & M & SD & Degree \\
\hline $\mathbf{1 2}$ & The club management is working to overcome obstacles during the emergence of the crisis & $\mathbf{2 . 4 5}$ & $\mathbf{0 . 3}$ & Moderate \\
\hline $\mathbf{1 3}$ & The club management distributes responsibilities to the members to deal with the crisis. & $\mathbf{2 . 4 0}$ & $\mathbf{0 . 1 2}$ & Moderate \\
\hline $\mathbf{1 4}$ & The club management delegates powers to the crisis team to deal with the crisis & $\mathbf{2 . 3 2}$ & $\mathbf{0 . 1}$ & Moderate \\
\hline $\mathbf{1 5}$ & There are plans and programs prepared in advance for how to deal with the crisis & $\mathbf{2 . 1 2}$ & $\mathbf{0 . 0 2}$ & Low \\
\hline $\mathbf{1 6}$ & In the club there is a trained team capable of dealing with a crisis when it occurs & $\mathbf{2 . 0 1}$ & $\mathbf{0 . 0 1}$ & Low \\
\hline $\mathbf{1 7}$ & $\begin{array}{l}\text { In the club's management there is a clear organizational structure that allows for dealing } \\
\text { with the crisis. }\end{array}$ & $\mathbf{1 . 9}$ & $\mathbf{0 . 1}$ & Low \\
\hline $\mathbf{1 8}$ & There is continuous cooperation between club management and local authorities & $\mathbf{1 . 8}$ & $\mathbf{0 . 2}$ & Low \\
\hline Total & & $\mathbf{2 . 1 5}$ & $\mathbf{0 . 1 2}$ & Low \\
\hline
\end{tabular}

Table 4. Means and standard deviations of the participants' responses to the crisis management elements related to the "damage containment stage"

\begin{tabular}{|l|l|c|c|c|}
\hline No & Statement & M & SD & Degree \\
\hline $\mathbf{1 9}$ & The club's management is dealing with the crisis in a manner consistent with its nature & $\mathbf{1 . 6 7}$ & $\mathbf{0 . 1}$ & Low \\
\hline $\mathbf{2 0}$ & The club management has the ability to take appropriate decisions to reduce crises. & $\mathbf{1 . 5 7}$ & $\mathbf{0 . 4}$ & Low \\
\hline $\mathbf{2 1}$ & The club management gives the crisis team an appropriate time to deal with the crisis & $\mathbf{1 . 4 5}$ & $\mathbf{0 . 1 5}$ & Low \\
\hline $\mathbf{2 2}$ & The factors causing the crisis are controlled within an appropriate period of time & $\mathbf{1 . 3}$ & $\mathbf{0 . 2 5}$ & Low \\
\hline $\mathbf{2 3}$ & The club management works to prevent a crisis that may result from the main crisis & $\mathbf{1 . 2}$ & $\mathbf{0 . 0 9}$ & Low \\
\hline Total & & $\mathbf{1 . 4 3}$ & $\mathbf{0 . 1 6}$ & Low \\
\hline
\end{tabular}

Table 5. Means and standard deviations of the participants' responses to the crisis management elements related to the "recovery stage"

\begin{tabular}{|l|l|c|c|c|}
\hline No & Statement & M & SD & Degree \\
\hline $\mathbf{7}$ & The club management collects detailed data in the places affected by the crisis. & $\mathbf{3 . 3 2}$ & $\mathbf{0 . 1 2}$ & Moderate \\
\hline $\mathbf{8}$ & The club management reviews the plans necessary to fulfill the duties after the end of the crisis. & $\mathbf{3 . 1 5}$ & $\mathbf{0 . 3}$ & Moderate \\
\hline $\mathbf{9}$ & $\begin{array}{l}\text { The club management works by directing thought and action to achieve the goals of the club } \\
\text { after the end of the crisis. }\end{array}$ & $\mathbf{3 . 0 1}$ & $\mathbf{0 . 1}$ & Moderate \\
\hline $\mathbf{1 0}$ & $\begin{array}{l}\text { The club's management is working to determine the needs necessary for the practice of its } \\
\text { normal activity. }\end{array}$ & $\mathbf{2 . 9}$ & $\mathbf{0 . 1 5}$ & Moderate \\
\hline $\mathbf{1 1}$ & The club management is involved in bringing about change by addressing the crisis & $\mathbf{2 . 7 8}$ & $\mathbf{0 . 0 1}$ & Moderate \\
\hline \multicolumn{2}{|l|}{ Total } & $\mathbf{3 . 0 3}$ & $\mathbf{0 . 1 3}$ & Moderate \\
\hline
\end{tabular}

The results shown in table (3) indicated that statement number 13 stating that "The club management is working to overcome obstacles during the emergence of the crisis" was ranked first with a mean score of (2.45) and a standard deviation of (0.3). In addition, the results showed that the statement number 18 was ranked as the lowest with a mean score of (2.15) and a standard deviation of (0.12), which indicated a low degree of availability.

The results shown in table (4) indicated that statement number 19 stating that "The club's management is dealing with the crisis in a manner consistent with its nature" was ranked first with a mean score of (1.67) and a standard deviation of $(0.1)$, whereas the $23^{\text {rd }}$ statement stating that "The club management works to prevent a crisis that may result from the main crisis" was ranked as lowest with a mean score of (1.2) and a standard deviation of (0.09), which indicated a low level of availability. The score of the whole domain was $(1.43 \pm 0.16)$, which indicated a low degree of availability.

The results shown in table (5) indicated that the $7^{\text {th }}$ statement stating that "The club management collects detailed data in the places affected by the crisis" was ranked first with a mean score of (3.32) and a standard deviation of (0.12), which indicated a moderate degree of availability, whereas the $11^{\text {th }}$ statement stating that "The club management is involved in bringing about change by addressing the crisis" was ranked the lowest with a mean score of (2.78) and a standard deviation of (0.01), which indicated a moderate degree of availability. The total score of the domain was $(3.03 \pm 0.13)$, which indicated a moderate degree of availability. 
Table 6. Means and standard deviation of the participants' responses to the crisis management elements related to the "Learning stage"

\begin{tabular}{|c|c|c|c|c|}
\hline No & Statement & M & $\mathrm{SD}$ & Degree \\
\hline 1 & The club's management benefits from lessons learned from the previous crises. & 4.45 & 0.2 & High \\
\hline 2 & The club's management reviews plans for dealing with crises in other institutions and clubs. & 4.25 & 0.01 & High \\
\hline 3 & The club's management is reviewing all its procedures related to the crisis & 3.98 & 0.3 & High \\
\hline 4 & The club management adopts creative thinking in dealing with crises & 3.7 & 0.1 & High \\
\hline 5 & $\begin{array}{l}\text { The club management is explaining the detailed steps that have been taken to deal with the } \\
\text { crisis }\end{array}$ & 3.5 & 0.1 & Moderate \\
\hline 6 & The club's management is working on developing crisis management programs and plans & 3.45 & 0.14 & Moderate \\
\hline \multicolumn{2}{|c|}{ Total } & 3.88 & 0.14 & High \\
\hline
\end{tabular}

Table 7. Means and standard deviations of the participants' responses on the domains of the degree of the availability of crisis management element among board of directors of sports clubs based on the variables (administrative experience, educational qualification, team rank)

\begin{tabular}{|l|l|c|c|c|}
\hline Variable & Variable categories & $\mathrm{n}$ & $\mathrm{M}$ & $\mathrm{SD}$ \\
\hline \multirow{2}{*}{$\begin{array}{l}\text { Administrative } \\
\text { Experience }\end{array}$} & Less than 5 years & $\mathbf{1 0 8}$ & $\mathbf{2 . 8 9}$ & $\mathbf{0 . 0 2}$ \\
\cline { 2 - 5 } & More than 5 years & $\mathbf{1 0 2}$ & $\mathbf{3 . 2}$ & $\mathbf{0 . 0 1}$ \\
\hline \multirow{3}{*}{ Educational qualification } & Secondary & $\mathbf{5 0}$ & $\mathbf{2 . 4 5}$ & $\mathbf{0 . 1 0}$ \\
\cline { 2 - 5 } & Diploma & $\mathbf{6 5}$ & $\mathbf{2 . 6 8}$ & $\mathbf{0 . 0 0 2}$ \\
\cline { 2 - 5 } & University & $\mathbf{9 3}$ & $\mathbf{3 . 3}$ & $\mathbf{0 . 0 3}$ \\
\hline \multirow{3}{*}{ Team rank } & First & $\mathbf{1 2 5}$ & $\mathbf{2 . 9}$ & $\mathbf{0 . 3 3}$ \\
\cline { 2 - 5 } & Professional & $\mathbf{8 1}$ & $\mathbf{3 . 4 5}$ & $\mathbf{0 . 1 5}$ \\
\hline \multirow{2}{*}{ Total Availability degree } & & $\mathbf{2 0 6}$ & & \\
\hline
\end{tabular}

Table 8. ANOVA test results for the statistical significant differences in the availability crisis management elements referred to the variables (Administrative experience, educational qualification, team rank)

\begin{tabular}{|c|c|c|c|c|c|c|}
\hline Variable & Source of variation & Sum of squares & df & Mean sum of squares & F-test & Sig \\
\hline \multirow{2}{*}{$\begin{array}{l}\text { Administrative } \\
\text { Experience }\end{array}$} & Between groups & 4.231 & 2 & 4.231 & \multirow{2}{*}{19.67} & \multirow{2}{*}{0.01} \\
\hline & Within groups & 19.56 & 206 & 0.215 & & \\
\hline \multirow{2}{*}{ Educational qualification } & Between groups & 3.58 & 2 & 3.58 & \multirow{2}{*}{11.01} & \multirow{2}{*}{0.002} \\
\hline & Within groups & 18.15 & 206 & 0.325 & & \\
\hline \multirow{2}{*}{ Team rank } & Between groups & 4.56 & 2 & 4.56 & \multirow{3}{*}{14.07} & \multirow{3}{*}{0.003} \\
\hline & Within groups & 20.152 & 206 & \multirow{2}{*}{0.324} & & \\
\hline \multicolumn{3}{|c|}{ Total } & 208 & & & \\
\hline
\end{tabular}

The results shown in table (6) indicated that the $1^{\text {st }}$ statement stating that "The club's management benefits from lessons learned from the previous crises" was ranked first with a mean score of (4.45) and a standard deviation of $(0.2)$, whereas the $6^{\text {th }}$ statement stating that "The club's management is working on developing crisis management programs and plans" was ranked the lowest with a mean score of (3.45) and a standard deviation of (0.14). The whole domain obtained a means score of (3.88) and a standard deviation of (0.14), which indicated a high degree of availability.

Second question: are there any significant statistical differences in the availability of crisis management elements in the boards of directors of Jordanian sports clubs referred to the variables (administrative experience, educational qualification, team rank)?

The results shown in table (7) present the mean scores and standard deviations of the difference in the availability of the crisis management elements among the board of directors of Jordanian sports clubs referred to the variables (administrative experience, educational qualification, team rank). To determine the level of statistical significance of these differences, ANOVA test was performed as indicated in table (8).

Table (8) presents the significant differences using ANOVA test. The results showed that there were no significant statistical differences as the $\mathrm{F}$ value for the administrative experience variable was 19.67 at a level of significance (0.01), which is not statistically significant. For the educational qualification variable, $F$ value was (11.01) at level of significance (0.01), which is no statistically significant. Finally, for the team rank variable, $F$ value was (14.07) at significance level of 0.01 , which is not statistically significant. 


\section{Discussion}

The results of the study showed that the degree of availability of crisis management elements was at a moderate degree, where the mean scores of the participants' responses as a whole was (2.31) with a standard deviation $(0.15)$. The researchers attributed this to the fact that the boards of directors of sports clubs are concerned with and working on the issue of crisis management and seek to be serious in preparing for any emergency, which reflects the interest of the boards of directors of clubs in the issue of crisis management. As well as global trends and the Jordanian Football Association's interest in offering theoretical lectures aimed at introducing members of club administrations to approaches in managing crises. This result is consistent with Al-Masaadeh [9] and Al Farazi [14] study, which reported a moderate degree of availability of crisis management elements. Learning domain was in the first rank and achieved a high degree for the availability of crisis management elements, meaning that the theoretical knowledge of the departments is present, but at a high degree, and it explains that the strategies of the boards of directors take the issue of crisis management very significantly during the planning process

The domain of alarm detection stage ranked last among the domains of study got a low grade. The researchers explain that the follow-up and implementation process among the employees responsible for managing the crisis in the club are accomplished systematically and based on periodic follow-up to discover and predict the occurrence of the crisis. Besides, the administration does not work on the interim evaluation of the crisis management team, and conducting mock drills of hypothetical crises that may occur in the future.

The results of this study also indicate that the statement "The club management benefits from lessons from the previous crises" had the highest score between the statements with a mean score (4.45) and a standard deviation (0.2), and this result is consistent with the results of Admns and kristonis [16], which confirmed that the schools that have been exposed to crises previously set up effective plans for managing crises in the future, and this confirms that club administrations benefit and learn from the errors they commit.

The statement "The club management has an administrative team capable of analyzing the indicators of the occurrence of the crisis" got the lowest level among the statements. This confirms that sports clubs do not have a specialized and qualified crisis management team capable of analyzing the causes of the occurrence of the crisis and this is reflected on the consequences of the crisis in the club. The researchers referred that to that the clubs' administrations are constantly changing every two years, meaning new people are elected to the administration, and this is one of the reasons that help the lack of experts in the field of crisis management in many clubs.

The study found that there are no differences among club boards of directors referred to the administrative experience, educational qualification or team rank. The researchers referred this to that the concept of crisis management became an overwhelming concern for those who are involved in the administrative field, and that the local, Asian, and international federations are focusing on the topic of crisis management. Our experience with the current Coronavirus pandemic has affected the response of board members because more than a year has passed since the crisis, and this indicates the administration's interest in the issue of crisis management. This result is in line with the findings reported by Al-Momani [8] and Al-Farazai [14], which indicated that there were no significant statistical differences between the participants' responses referred to the study variables. The researchers referred this result to that the members of club boards of directors do not work to improve their administrative capabilities during their service in the club, and for this reason there were no differences referred to years of administrative experience, as well as educational qualification or the rank of the club, and this indicates that the boards of directors of clubs work with similar approaches and administrative level in dealing with the crises to which they are exposed.

\section{Recommendations}

In light of the results of the study, the study provides the following recommendations:

First: The necessity of activating the role of crisis management elements in sports bodies and institutions, as they have a crucial role in reducing the undesired consequences of crises.

Second: The need to benefit from the experiences of others in the field of crisis management and to develop effective plans and strategies in dealing with emergent crises.

Third: Enacting legislations and laws requiring members of sports club boards to take training courses in the field of crisis management.

Fourth: Conducting empirical studies in the field of comparison between local and international clubs in the field of crisis management

\section{REFERENCES}

[1] Wilson, B. "Crisis Management: A case study of three American universities", Ph.D Dissertation Abstracts University of Pittsburgh Database, Yarmouk University, Jordan. 1992.

[2] Muftah, A. "Sports Administration and its Role in 
Improving Facilities Management, Field Study of Youth and Sports Directorate in Al-Masela Province", Institute of Sciences and Techniques of Physical Activities and Sports, Al-Muhtaref Journal, Vol 23., no. 6. 2018.

[3] Jamil, A. "Crisis and Disaster Management", Amman: Al-Janadriyah House for Publishing and Distribution. 2016.

[4] Esleem, W. S. M. "Features of Crisis Management in Palestinian Governmental Institutions", Field Study on the Ministry of Finance in Gaza, Master Thesis, Islamic University, Gaza, Palestine. 2007.

[5] Phelps, L. "Setting up A crisis: recovering Plan", Journal of Business Strategy, Vol 4., no. 6, 2003.

[6] Qutaish, N. "Crisis Management". Amman: Al Raya House for publication and distribution,. 2009.

[7] Al-Hafni, S. A. A. "Crisis Management, Journal of Financial and Business Research", Port Said University, Egypt, 2017.

[8] Al-Momani, Z. "Modern administrative concepts in sports management", 2nd Edition, Jordan: The National Library Department.2020.

[9] Al-Masaadeh, J. "Elements of Crisis Management and Its Barriers in Sports Institutions in Jordan", Master Thesis, Yarmouk University, Jordan. 2002.

[10] Ashour, M. "The degree of perception of department heads at Yarmouk University of the availability of crisis management elements". Umm Al-Qura University Journal of Educational and Psychological Sciences, Makkah, Saudi Arabia, 2011, 3 (1): 121-195

[11] Al-Maharmeh, Y. "Obstacles to Crisis Management in Sports Activity departments in Jordanian Universities from the Viewpoint of Directors of Sports Activity departments", Al-Mishkat Journal, International Islamic Sciences University, Vol 1, no. 2, pp. 109-123, 2013.

[12] Alshamrani, S. "Elements of Crisis Management and Its
Barriers in Higher Education Institutions in the Kingdom of Saudi Arabia", Master Thesis, Yarmouk University, Jordan, 2013.

[13] Al-Mansouri, S. "Development of administrative behavior in the public secondary school in the State of Qatar using the approach of crisis management", PhD thesis, Ain Shams University, Cairo, Egypt, 2008.

[14] Al-Farazi, M. "Crisis Management Development in the Preparatory and Secondary Schools in the Sultanate of Oman", Master Thesis, Sultan Qaboos University, Oman, 2003.

[15] Birkland, T. "Disasters Lessons Learned and Fantasy documents", Journal of gontingevcies and Crisis management, Vol., 17, no., 30, pp. 35-61, 2009.

[16] Admns. C. and Kristina's. W. "An Analysis of secondary school crisis management preparedness", National Journal for publishing and mentoring Doctoral students Research, Vol 3., no. 2, pp. 41-59, 2006.

[17] Abdel Aal, R. F. "Crisis Management Practices for Public School Principals in the Open Jerusalem During the Al-Aqsa Intifada", Journal of Al-Quds Open University for Studies and Research, Vol 2., no. 1, pp. 30-99, 2008.

[18] Al-Senani, M. F. O. "Crisis Management Barriers at Imam Muhammad bin Saud Islamic University from the point of view of faculty deans, department heads, their agents", Master Thesis, Imam Muhammad bin Saud Islamic University, Riyadh, 2010.

[19] Kemala, A., Aini, K., and Mamesah, E. "Jakarta Athletics Training during the COVID-19", International Journal of Human Movement and Sport Sciences, Vol 8., no., 6A, pp. 57-62, 2020.

[20] Nedal Ahmad Alghafary, "The Availability of the $21^{\text {st }}$ Century Skills in the Sport and Health for All Curriculum of the Undergraduate University Students in Al-Balqaa Applied University, Jordan," International Journal of Human Movement and Sports Sciences, Vol. 8, No. 5, pp. 217 - 228, 2020. DOI: 10.13189/saj.2020.080509. 